\title{
GMR
}

\section{Nucleotide variation in the Toxoplasma gondii micronemal protein 8 gene}

\author{
Z.Y. Li ${ }^{1,2}$, H.Q. Song ${ }^{2}$, C.R. Wang ${ }^{1}$ and X.Q. Zhu ${ }^{1,2}$ \\ ${ }^{1}$ College of Animal Science and Veterinary Medicine, \\ Heilongjiang Bayi Agricultural University, Daqing, Heilongjiang Province, \\ China \\ ${ }^{2}$ State Key Laboratory of Veterinary Etiological Biology, \\ Key Laboratory of Veterinary Parasitology of Gansu Province, \\ Lanzhou Veterinary Research Institute, \\ Chinese Academy of Agricultural Sciences, Lanzhou, Gansu Province, China \\ Corresponding author: C.R. Wang \\ E-mail: chunrenwang@sohu.com \\ Genet. Mol. Res. 15 (2): gmr.15028578 \\ Received February 24, 2016 \\ Accepted April 8, 2016 \\ Published May 6, 2016 \\ DOI http://dx.doi.org/10.4238/gmr.15028578
}

\begin{abstract}
Toxoplasmagondii is a successful opportunistic protozoan distributed worldwide, which can infect all vertebrates, leading to serious infection, blindness, and abortion. Micronemal (MIC) proteins are critically important for $T$. gondii infection, as they participate in various stages of the Toxoplasma life cycle, including invasion and attachment to host cells. MIC8 secretion relies on the concentration of intracellular calcium, and can mediate the invasion of $T$. gondii by interacting with soluble MIC3. To investigate genetic diversity of the MIC8 gene, 16 T. gondii strains from different hosts and geographical locations, and two reference isolates (ToxoDB: TGME49_245490 and TGVEG_245490) were examined in this study. The results showed that all the examined MIC8 genes are $2055 \mathrm{bp}$, with an A+T content ranging from 50.2 to $50.6 \%$. Conversely, lower levels of variation were detected within their nucleotide and amino acid sequences. Phylogenetic analyses indicated that three classical genotypes of $T$. gondii and the
\end{abstract}


ToxoDB\#9 genotype did not group exclusively via Bayesian inference, maximum parsimony, neighbor joining, and/or maximum likelihood assays based on the nucleotide and amino acid sequences of the MIC8 gene. In summary, the T. gondii MIC8 gene is not a suitable marker for population genetic studies of this parasite.

Key words: Toxoplasma gondii; Toxoplasmosis; MIC8; Genotyping; Sequence variation

\section{INTRODUCTION}

As one of the most successful opportunistic pathogens, the obligate intracellular parasite Toxoplasma gondii can infect a wide range of animals including mammals, birds, and humans (Kim and Weiss, 2008; Cenci-Goga et al., 2011) and cause severe diseases, including congenital neurological defects in humans (Blanchard et al., 2015; Giakoumelou et al., 2016) and some symptomatic infections in immuno-compromised patients (Robert-Gangneux and Dardé, 2012). The parasite can also lead to abortion and fetal abnormalities in livestock, resulting in serious economic losses (Dubey et al., 2005; Innes, 2010).

Many studies have shown that different clonal $T$. gondii strains with diverse geographical distributions possess different virulence in humans and animals (Sibley and Ajioka, 2008; Robert-Gangneux and Dardé, 2012). Despite the variety of hosts and cell types infected, the asexual life cycle of $T$. gondii consists of one intracellular stage (replication) and four motile stages (egress from the host cell, motility, attachment, and invasion) and is highly conserved (Opitz and Soldati, 2002; McCoy et al., 2012).

Micronemal proteins (MICs) are serially secreted from micronemes during T. gondii infection, and play a significant role in the asexual life cycle of this parasite by mediating parasite invasion, motility, and attachment to host cells (Besteiro et al., 2011; Muniz-Feliciano et al., 2013; Sharma and Chitnis, 2013). As an important member of the MIC family, MIC8 participates in T. gondii invasion through interaction with soluble MIC3 (Cérède et al., 2002; Kessler et al., 2008), and is a potential vaccine candidate against acute and chronic T. gondii infections in a mouse model (Liu et al., 2010; Li et al., 2014). To investigate the genetic diversity of the MIC8 gene, 16 T. gondii strains from different hosts and geographical locations, and two reference isolates were examined in this study.

\section{MATERIAL AND METHODS}

\section{T. gondii isolates}

Sixteen T. gondii strains from different hosts and geographical locations (Table 1) and two reference isolates (ToxoDB: TGME49_245490 and TGVEG_245490) were used in this study. Wizard ${ }^{\circledR}$ SV Genomic DNA Purification System (Promega, USA) was used to extract genomic DNA (gDNA) according to the manufacturer instruction.

\section{Polymerase chain reaction (PCR) amplification}

To amplify the MIC8 gene from each Toxoplasma strain, one pair of specific 
primers (forward primer, 5'-ATGAAGGCCAATCGAATATGGTG-3'; reverse primer, 5'-TTAGGACCAGATACCGCCCGAA-3') was designed using Oligo 6.0 software according to the reference sequence of the ME49 isolate (ToxoDB: TGME49_245490). PCR amplifications were performed in a final volume of $25 \mu \mathrm{L}$ containing $0.5 \mu \mathrm{L} 20 \mu \mathrm{M}$ each primer, 100-200 ng gDNA, and $12.5 \mu \mathrm{L}$ Premix ExTaq ${ }^{\circledR}$ Version 2.0 (TaKaRa, Dalian, China). gDNA samples were amplified in a thermocycler (BioRad, USA) at $95.0^{\circ} \mathrm{C}$ for $10 \mathrm{~min}$ followed by 30 cycles composed of $95.0^{\circ} \mathrm{C}$ for $45 \mathrm{~s}, 57.9^{\circ} \mathrm{C}$ for $30 \mathrm{~s}$, and $72.0^{\circ} \mathrm{C}$ for $2 \mathrm{~min}$, and a final extension step at $72.0^{\circ} \mathrm{C}$ for $10 \mathrm{~min}$. After confirmation using electrophoresis on $1.0 \%(\mathrm{w} / \mathrm{v})$ agarose gel, all PCR products were purified using the Wizard ${ }^{\mathrm{TM}}$ PCR-Preps DNA Purification System (Promega), ligated with pMD18-T vector (TaKaRa), and transfected into competent DH5 $\alpha$ Escherichia coli cells (Promega). Single colonies confirmed through PCR amplification were sequenced in triplicate by Sangon Biological Engineering Biotechnology Company (Shanghai, China) (Chen et al., 2014; Li et al., 2015a).

Table 1. Details of the Toxoplasma gondii strains used in this study.

\begin{tabular}{l|l|l|l|l}
\hline No. & Isolate & Host & Geographical location & Genotype* \\
\hline 1 & RH & Human & France & Reference, Type I, ToxoDB \#10 \\
\hline 2 & GT1 & Goat & United States & Reference, Type I, ToxoDB\#10 \\
\hline 3 & TgPLH & Pig & Henan, China & Type I, ToxoDB \#10 \\
\hline 4 & PRU & Human & France & Type II, ToxoDB \#1 \\
\hline 5 & QHO & Sheep & Qinghai, China & Type II, ToxoDB \#1 \\
\hline 6 & PTG & Sheep & United States & Reference, Type II, ToxoDB\#1 \\
\hline 7 & CTG & Cat & United States & Reference, Type III, ToxoDB\#2 \\
\hline 8 & ggWtdSc40 & Deer & USA & Type 12, ToxoDB\#5 \\
\hline 9 & PYS & Pig & Panyu, China & ToxoDB \#9 \\
\hline 10 & GJS & Pig & Jingyuan, Gansu, China & ToxoDB \#9 \\
\hline 11 & TgC7 & Cat & Guangzhou, China & ToxoDB \#9 \\
\hline 12 & TgCatBr5 & Cat & Brazil & Reference, ToxoDB\#19 \\
\hline 13 & TgCatBr64 & Cat & Brazil & Reference, ToxoDB\#111 \\
\hline 14 & TgToucan & Toucan & Costa Rica & Reference, ToxoDB\# $\# 2$ \\
\hline 15 & MAS & Human & France & Reference, ToxoDB\#\#17 \\
\hline 16 & TgCgCa1 & Cougar & Canada & \\
\hline
\end{tabular}

*Based on the report of Su et al. (2010).

\section{Sequence analysis and phylogenetic reconstruction}

All the obtained sequences were aligned by Clustal X 2.11 (Thompson et al., 1997), and evolutionary analyses were performed using MEGA 5.2 (Tamura et al., 2011). Bayesian inference (BI), maximum parsimony (MP), neighbor joining (NJ), and maximum likelihood (ML) analyses were performed for phylogenetic reconstructions based on the MIC8 nucleotide and amino acid sequences according to previously described methods (Swofford, 2002; Ronquist and Huelsenbeck, 2003; Chen et al., 2012). Intra-specific sequence variations were examined using the percentage of different bases.

\section{RESULTS AND DISCUSSION}

Agarose gel electrophoresis of the MIC8 PCR products revealed a single band of approximately $2000 \mathrm{bp}$ in length (data not shown). All the examined MIC8 genes were 2055bp long, which was confirmed by sequencing in triplicate, and their $\mathrm{A}+\mathrm{T}$ content was between 50.2 and 50.6\%, respectively. This is higher than that of MIC6 ( $\mathrm{Li}$ et al., 2015c), ROP8 (Li 
et al., 2015a), ROP20 (Ning et al., 2015), ROP38 (Xu et al., 2014), ROP47 (Wang et al., 2015),

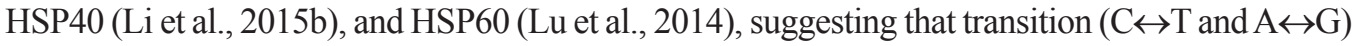
and transversion $(\mathrm{A} \leftrightarrow \mathrm{C}, \mathrm{A} \leftrightarrow \mathrm{T}, \mathrm{G} \leftrightarrow \mathrm{T}$ and $\mathrm{G} \leftrightarrow \mathrm{C}$ ) might have occurred in the MIC8 gene.

Sequence alignment revealed that 25 mutant nucleotide positions $(0-0.34 \%)$ compared to the T. gondii RH strain are lower than that of ROP38 (Xu et al., 2014), GRA5 (Chen et al., 2012), and GRA6 (Fazaeli et al., 2000), and result in 17 amino acid substitutions (0-0.73\%) (Figure 1). Our data indicate there are lower rates of variation in the amino acid sequence of the MIC8 gene among different genotypes of $T$. gondii, suggesting that the MIC8 protein may be a potential vaccine candidate against acute and chronic $T$. gondii infections, which has been demonstrated in our previous studies (Liu et al., 2010; Li et al., 2014).
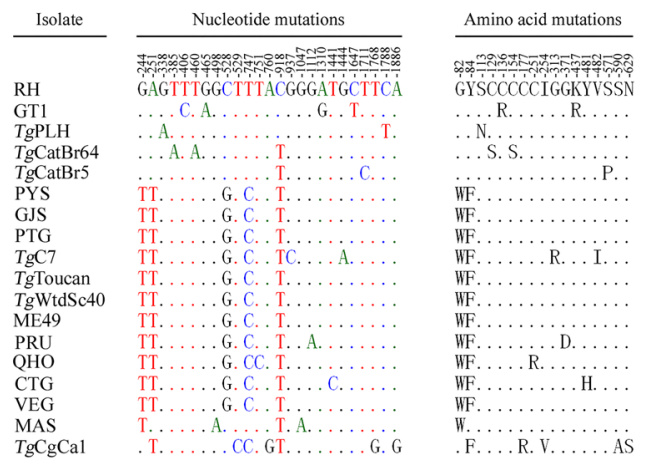

Figure 1. Mutations in the nucleotide and amino acid sequences of Toxoplasma gondii MIC8. The numbers indicate the variable positions of a nucleotide or amino acid; dot indicates an identical nucleotide or amino acid position in comparison with the $T$. gondii $\mathrm{RH}$ isolate (upper line).

Phylogenetic reconstructions were also performed based on the obtained MIC8 nucleotide and amino acid sequences using BI, MP, NJ, and/or ML analyses to assess whether MIC8 could be used as a novel marker for studying the evolutionary relationship of the examined T. gondii strains (Figure 2). The results showed that the three T. gondii classical genotypes (I, II, and III) and the ToxoDB\#9 genotype could not be completely separated. In summary, these data suggest that the T. gondii MIC8 gene is not suitable as a potential marker for population genetic studies of this parasite.

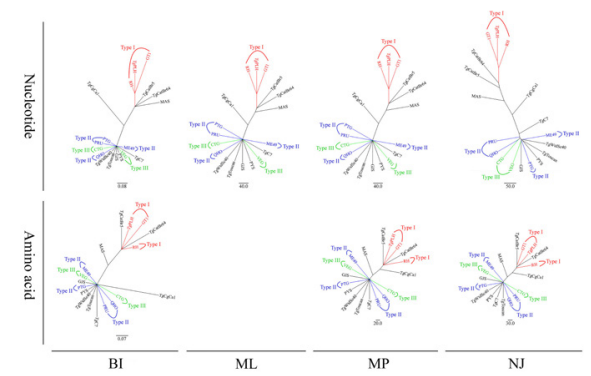

Figure 2. Phylogram showing 18 Toxoplasma gondii strains based on their MIC8 nucleotide and amino acid sequences through Bayesian inference (BI), maximum parsimony (MP), neighbor joining (NJ), and/or maximum likelihood (ML) analyses. ME49 (ToxoDB: TGME49_245490) and VEG (ToxoDB: TGVEG_245490) were used as the reference strains in the present study. 


\section{Conflicts of interest}

The authors declare no conflict of interest.

\section{ACKNOWLEDGMENTS}

Research partially supported by the National Natural Science Foundation of China (Grant \#31228022), and the Science Fund for Creative Research Groups of Gansu Province (Grant \#1210RJIA006).

\section{REFERENCES}

Besteiro S, Dubremetz JF and Lebrun M (2011). The moving junction of apicomplexan parasites: a key structure for invasion. Cell. Microbiol. 13: 797-805. http://dx.doi.org/10.1111/j.1462-5822.2011.01597.x

Blanchard N, Dunay IR and Schlüter D (2015). Persistence of Toxoplasma gondii in the central nervous system: a finetuned balance between the parasite, the brain and the immune system. Parasite Immunol. 37: 150-158. http://dx.doi. org $/ 10.1111 /$ pim. 12173

Cenci-Goga BT, Rossitto PV, Sechi P, McCrindle CM, et al. (2011). Toxoplasma in animals, food, and humans: an old parasite of new concern. Foodborne Pathog. Dis. 8: 751-762.http://dx.doi.org/10.1089/fpd.2010.0795

Cérède O, Dubremetz JF, Bout D and Lebrun M (2002). The Toxoplasma gondii protein MIC3 requires pro-peptide cleavage and dimerization to function as adhesin. EMBO J. 21: 2526-2536. http://dx.doi.org/10.1093/emboj/21.11.2526

Chen J, Li ZY, Zhou DH, Liu GH, et al. (2012). Genetic diversity among Toxoplasma gondii strains from different hosts and geographical regions revealed by sequence analysis of GRA5 gene. Parasit. Vectors 5: 279. http://dx.doi. org/10.1186/1756-3305-5-279

Chen J, Fang SF, Zhou DH, Li ZY, et al. (2014). Sequence variation in the Toxoplasma gondii eIF4A gene among strains from different hosts and geographical locations. Genet. Mol. Res. 13: 3356-3361.http://dx.doi.org/10.4238/2014. April.29.14

Dubey JP, Hill DE, Jones JL, Hightower AW, et al. (2005). Prevalence of viable Toxoplasma gondii in beef, chicken, and pork from retail meat stores in the United States: risk assessment to consumers. J. Parasitol. 91: 1082-1093. http:// dx.doi.org/10.1645/GE-683.1

Fazaeli A, Carter PE, Darde ML and Pennington TH (2000). Molecular typing of Toxoplasma gondii strains by GRA6 gene sequence analysis. Int. J. Parasitol. 30: 637-642.http://dx.doi.org/10.1016/S0020-7519(00)00036-9

Giakoumelou S, Wheelhouse N, Cuschieri K, Entrican G, et al. (2016). The role of infection in miscarriage. Hum. Reprod. Update 22: 116-133. http://dx.doi.org/10.1093/humupd/dmv041

Innes EA (2010). A brief history and overview of Toxoplasma gondii. Zoonoses Public Health 57: 1-7. http://dx.doi. org $/ 10.1111 / \mathrm{j} .1863-2378.2009 .01276 . \mathrm{x}$

Kessler H, Herm-Götz A, Hegge S, Rauch M, et al. (2008). Microneme protein 8 - a new essential invasion factor in Toxoplasma gondii. J. Cell Sci. 121: 947-956. http://dx.doi.org/10.1242/jcs.022350

Kim K and Weiss LM (2008). Toxoplasma: the next 100years. Microbes Infect. 10: 978-984. http://dx.doi.org/10.1016/j. micinf.2008.07.015

Li ZY, Chen J, Petersen E, Zhou DH, et al. (2014). Synergy of mIL-21 and mIL-15 in enhancing DNA vaccine efficacy against acute and chronic Toxoplasma gondii infection in mice. Vaccine 32: 3058-3065. http://dx.doi.org/10.1016/j. vaccine.2014.03.042

Li ZY, Chen J, Lu J, Wang CR, et al. (2015a). Sequence variation in ROP8 gene among Toxoplasma gondii isolates from different hosts and geographical localities. Genet. Mol. Res. 14: 11403-11409. http://dx.doi.org/10.4238/2015. September.25.8

Li ZY, Lu J, Zhou DH, Chen J, et al. (2015b). Sequence variation in HSP40 gene among 16 Toxoplasma gondii isolates from different hosts and geographical locations. BioMed Res. Int. 2015: 209792.

Li ZY, Song HQ, Chen J and Zhu XQ (2015c). Sequence diversity in MIC6 gene among Toxoplasma gondii isolates from different hosts and geographical locations. Korean J. Parasitol. 53: 341-344. http://dx.doi.org/10.3347/ kjp.2015.53.3.341

Liu MM, Yuan ZG, Peng GH, Zhou DH, et al. (2010). Toxoplasma gondii microneme protein 8 (MIC8) is a potential vaccine candidate against toxoplasmosis. Parasitol. Res. 106: 1079-1084. http://dx.doi.org/10.1007/s00436-010$\underline{1742-0}$ 
Lu J, Zhou DH, Chen J, Zhang NZ, et al. (2014). Characterization of the Toxoplasma gondii hsp60 gene sequences from different hosts and geographical locations. Genet. Mol. Res. 13: 6906-6911. http://dx.doi.org/10.4238/2014. August.29.13

McCoy JM, Whitehead L, van Dooren GG and Tonkin CJ (2012). TgCDPK3 regulates calcium-dependent egress of Toxoplasma gondii from host cells. PLoS Pathog. 8: e1003066.http://dx.doi.org/10.1371/journal.ppat.1003066

Muniz-Feliciano L, Van Grol J, Portillo JA, Liew L, et al. (2013). Toxoplasma gondii-induced activation of EGFR prevents autophagy protein-mediated killing of the parasite. PLoS Pathog. 9: e1003809. http://dx.doi.org/10.1371/ journal.ppat.1003809

Ning HR, Wang JL, Qin SY, Huang SY, et al. (2015). Sequence variation in the Toxoplasma gondii ROP20 gene among strains from different hosts and geographical locations. Genet. Mol. Res. 14: 8414-8419. http://dx.doi. org/10.4238/2015.July.28.8

Opitz C and Soldati D (2002). 'The glideosome': a dynamic complex powering gliding motion and host cell invasion by Toxoplasma gondii. Mol. Microbiol. 45: 597-604. http://dx.doi.org/10.1046/j.1365-2958.2002.03056.x

Robert-Gangneux F and Dardé ML (2012). Epidemiology of and diagnostic strategies for toxoplasmosis. Clin. Microbiol. Rev. 25: 264-296. http://dx.doi.org/10.1128/CMR.05013-11

Ronquist F and Huelsenbeck JP (2003). MrBayes 3: Bayesian phylogenetic inference under mixed models. Bioinformatics 19: 1572-1574. http://dx.doi.org/10.1093/bioinformatics/btg180

Sharma P and Chitnis CE (2013). Key molecular events during host cell invasion by Apicomplexan pathogens. Curr. Opin. Microbiol. 16: 432-437.http://dx.doi.org/10.1016/j.mib.2013.07.004

Sibley LD and Ajioka JW (2008). Population structure of Toxoplasma gondii: clonal expansion driven by infrequent recombination and selective sweeps. Аnпи. Rev. Microbiol. 62: 329-351. http://dx.doi.org/10.1146/annurev. $\underline{\text { micro.62.081307.162925 }}$

Su C, Shwab EK, Zhou P, Zhu XQ, et al. (2010). Moving towards an integrated approach to molecular detection and identification of Toxoplasma gondii. Parasitology 137: 1-11.http://dx.doi.org/10.1017/S0031182009991065

Swofford DL (2002). Paup*: phylogenetic analysis using parsimony, version 4.0b10. Sinauer Associates, Sunderland, MA.

Tamura K, Peterson D, Peterson N, Stecher G, et al. (2011). MEGA5: molecular evolutionary genetics analysis using maximum likelihood, evolutionary distance, and maximum parsimony methods. Mol. Biol. Evol. 28: 2731-2739. http://dx.doi.org/10.1093/molbev/msr121

Thompson JD, Gibson TJ, Plewniak F, Jeanmougin F, et al. (1997). The CLUSTAL_X windows interface: flexible strategies for multiple sequence alignment aided by quality analysis tools. Nucleic Acids Res. 25: 4876-4882. http:// dx.doi.org/10.1093/nar/25.24.4876

Wang JL, Li TT, Li ZY, Huang SY, et al. (2015). Rhoptry protein 47 gene sequence: A potential novel genetic marker for population genetic studies of Toxoplasma gondii. Exp. Parasitol. 154: 1-4. http://dx.doi.org/10.1016/j. exppara.2015.03.006

Xu Y, Zhang NZ, Chen J, Liu GH, et al. (2014). Toxoplasma gondii rhoptry protein 38 gene: sequence variation among isolates from different hosts and geographical locations. Genet. Mol. Res. 13: 4839-4844. http://dx.doi. org/10.4238/2014.January. 14.3 